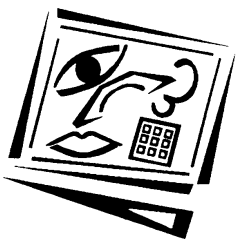

\title{
Prerequisites for interactive learning in distance education: Perspectives from Swedish students
}

\author{
Berit Östlund \\ Umeå University, Sweden
}

\begin{abstract}
This article investigates distance students' understanding of the prerequisites for interactive learning in asynchronous, computer mediated university distance studies. It encompasses students' attitudes to structure, dialogue and autonomy, and their experience of social presence and what they consider interaction with peer learners signifies for their learning. The data were collected from an undergraduate and a masters course within the teacher training distance program, using questionnaires, interviews, diaries and analysis of students' contributions in FirstClass and WebBoard respectively. The results indicate that there was no difference between the student groups in preferences concerning structure, dialogue and autonomy. Their preferences depended on their ideas about how to benefit from different situations. They preferred a course design permitting them to use time effectively in relation to their other commitments outside the university. The results also indicate that they felt social presence despite using only asynchronous, text based communication. The student groups, however, had different ideas about the significance of inter-learner interactions. The amount of spontaneous contributions sent to WebBoard and FirstClass also differed. The undergraduate students stressed the social and practical aspects, while the masters students to a greater extent emphasised the cognitive aspects. The amount of spontaneous interactions was also higher in the undergraduate group. These students need more support from others in order to manage their studies compared to the masters students.
\end{abstract}

\section{Introduction}

Distance courses and distance students have rapidly increased in numbers during the last decades, both in Sweden and internationally (Peters, 2003; Holmberg 2003; Högskoleverket 2004:16). The growing interest in distance education has resulted in increased research, including research on communication and interaction among distance students. This topic has been analysed mainly from social constructivistic or socio-cultural perspectives, which argue that learning is a social activity. Often these studies have focused on how different course design and technical communication tools influence the extent and nature of interactions between students. Many such studies have been based on one single distance course by researchers who themselves regard learning as a social activity. The results that are presented are strikingly often positive (Wallace 2003; Hammond, 2005).

However, other studies have concluded that interaction between distance students is often lacking (Hammond, 2000; Soller, 2001; Wännman Toresson, 2002). It has been argued that teachers and administrators are not aware of the requirements for encouraging communication and interaction in virtual learning environments. Distance teachers often take for granted the fact that distance students are able to 
function as a working group from the very beginning of the course. But becoming a functioning working group is a process that is developed step by step, where the first step is to create relationships and a sense of safety in the group (Kreijns, Krischner \& Jochems, 2004).

From a sociocultural perspective on learning, it is important to design distance courses which gives propitious opportunities for inter-learner interactions. In this context it is essential to be informed of the students' needs, preferences and experiences of distance learning. However, fewer studies have been conducted into distance students' apprehensions about prerequisites for interactive learning in asynchronous, computer mediated distance education. the issue discussed in this article.

\section{Theoretical concepts and starting points}

Different theories and perspectives have been used in order to study interaction in computer mediated distance education. The theories used in this article are transactional distance theory, the theory of social presence, and socio-cultural perspectives on knowledge and learning.

The first attempt to classify distance education appeared in 1972, when Michael Moore articulated a theory, later named transactional distance theory (TDT). Distance education, according to this theory, is a pedagogic concept describing the universe of teacherlearner relationships existing when they are separated by space and/or by time in an educational situation. Moore (1997) argued that physical distance creates a psychological and communicational space for potential misunderstandings between students and teachers. This space, which Moore refers to as transactional distance (TD), can influence students' motivation, participation and learning. Different arrangements in order to decrease TD are therefore necessary (Moore \& Kearsley, 1996). TD is a function of interplay among the variables structure, dialogue, and learner autonomy. Structure and dialogue comprise teaching procedures, whereas autonomy describes characteristics and behaviours of the learners (Moore, 1997).

Structure deals with questions about how the instructional program is designed to meet students' individual needs. It expresses the rigidity or flexibility of the course's educational objectives, teaching strategies and evaluation methods (Moore 1997).

Dialogue refers to a conscious, constructive, mutual and valued teacher-learner interaction aiming at supporting the students' learning process. The dialogue's extent and nature are determined by, among other things, the educational philosophy of the course organiser (e.g. the teacher), the medium for communication and how it is used, the number of students in the class, the teacher's and students' personalities, and the course's subject area (Moore, 1997).

Learner autonomy is determined by the students' scope and capacity to independently govern their own learning in courses with varying degrees of structure and dialogue (Moore, 1997).

The relationship between the variables is as follows (Moore, 1997):

- Increased structure decreases the extent of dialogue.

- TD and dialogue are inversely proportional, i.e. an increased extent of dialogue gives a decreased extent of TD and vice versa. 
- TD and learner autonomy are directly proportional, i.e. the greater TD the more autonomy students have to exercise in order to be successful.

It is more then 30 years since Moore developed TDT, but the theory has been refined continuously and it is still important in practical and theoretical terms. Several researchers consider TDT to be a basic analytical framework for understanding distance education systems. Researchers and instructional designers often cite the need to reduce TD when building effective learning environments, by balancing structure and dialogue and learner autonomy (Garrison, 2000; Jung, 2001; Kanuka et.al., 2002; Martindale 2002; Moore, 2007).

However, the theory has also been criticised. Gorsky and Caspi (2005) found, for instance, that very few studies have been conducted to test the validity of the key constructs and the relationships among them. They also found that TDT was neither supported nor validated by these studies because the reliability and construct validity in the studies was limited. Furthermore, Gorsky and Caspi (2005) argue that TDT may be reduced to a single proposition i.e., as dialogue increases, TD decreases and that this proposition may be a tautology.

The most important evolution in distance education, since TDT was articulated for the first time, is the development of digital communication technologies and the Internet. The new techniques have a direct impact on the extent and quality of dialogue between teachers and students (Moore, 1997). These also create possibilities for developing instructional models based on social constructivistic or socio-cultural perspectives on knowledge and learning. These theories are influenced by Vygotsky, who argued that learning is a social activity. Through mutual exchange of information, attitudes and experiences, students can gain deeper understanding and broader knowledge (Säljö, 2000).

Interactions between people have content and a purpose, that can be cognitive, practical or social. It has been shown that the practical content is as important as the cognitive for successful studies, especially for students unfamiliar with university studies and distance learning (Kear, 2001). Social and emotional interaction is important because the social climate affects the learning process. These interactions can be crucial for students to be successful in their studies since encouragement and acknowledgement are essential for motivation and learning (Rovai, 2001; Rourke et al., 2001).

Short et al (1976) founded social presence theory (SPT) to describe how social presence (SP) occurs in different environments and through diverse media. They argue that the medium's capacity to convey the salience of an interaction partner, based on the medium's ability to transmit social cues as non-verbal and vocal expressions, influences the amount and quality of interactions between people. When SP is high, communicators feel more engaged and involved in group processes (Short et al., 1976). As the ability for people to interact effectively is central in the theory, it is of interest to course designers when planning for collaborative learning in computer mediated distance education (Wheeler, 2005).

A concern among some educators has been that computer mediated communications prevent students from developing a sense of connection to educational institutions, instructors and peer learners (Haythornthwaite, 2002). It has also been argued that interactions will be reduced because social cues as non-verbal expressions are limited, 
especially in text based asynchronous learning environments. Sproull and Kiesler (1986), for example, found that a lack of social cues led to intense and hostile language and greater self absorption. Daft and Lengel (1986) showed that absence of non-verbal information resulted in short, pragmatic interchanges.

However, more recent studies demonstrate that SP and interpersonal interactions are supported in online environments. These studies show that students express openness and solidarity in their online contributions: expressions of feelings and humour, self introductions, greetings and closers (Hara, Bonk \& Angeli 2000). It has been found also that people compensate for the absence of non-verbal cues in written communication by using emoticons or other meta-linguistic cursors (Gunawardena \& Zittle, 1997; Swan 2003).

Several studies indicate that distance students are more successful in computer mediated distance education and better motivated to interact if they perceive SP, trust and solidarity within a study group (Gunawardena \& Zittle, 1997; Picciano, 2002; Walther 2002; Kreijns, Krischner, \& Jochems, 2004; Richardson \& Swan, 2003; Swan \& Shih, 2005). It is also essential that the students have knowledge about the communication technology and how to use it to promote effective collaborative learning (Soller, 2001).

\section{Research questions}

This article investigates distance students' understanding of the prerequisites for interactive learning in asynchronous, computer mediated university distance studies. The students' experiences of and attitudes to structure, dialogue and autonomy are in focus. This study stresses the dialogue among students, with the concept of interaction being used here synonymously with dialogue. Furthermore, one purpose is to investigate students' experience of social presence and what they consider interaction with peer learners signifies for study and learning.

Two university courses are investigated, one a basic level course and the other an advanced level course. The student groups differed in prior knowledge about the course's subject areas and in experience of higher education and distance studies (Table 1). Important questions for the study are:

- What are the students' attitudes to, and experiences of, structure, dialogue and autonomy?

- What motivates the students to interact with each other? What importance do the students ascribe to interaction with peer learners? For what purpose do the students interact with each other? Do the students experience social presence despite geographical separation?

- Are there any differences between the two courses concerning the above questions?

\section{Description of the students and the courses}

The data were collected in 2003 from two distance courses within the teacher training program. Course 1 was a 13 week, full time, introductory course, within a 3-year undergraduate program. The subject area was counselling. Course 2 covered the last 20 weeks of a 40 week, 'half speed' Masters course in special education. The academic year in Sweden is divided into two semesters and each course is measured in credit points. One credit point is the equivalent of one week of full time studies (40 working 
hours per week) or two weeks of 'half speed' studies (20 working hours per week). Course 1 is according to this a 13 credit points course and course 2 corresponds to 10 credit points of a 20 credit points course.

The courses were similarly designed, with a high degree of structure. The students had few possibilities to influence the content or the course arrangement. The courses followed set curricula with a predetermined literature list and had meetings on campus (10+2 days in course 1, 3 × 3 days in course 2$)$ with compulsory elements. The study guides contained strict instructions about what to read and how assignments should be carried out, together with a timetable for when the assignments were to be sent in to the conference. Apart from individual assignments, both courses included three assignments with requirements for interaction e.g. contribute in discussions or give feedback to peer learners' texts. There were instructions about the number of contributions requested from each student. The students were divided into smaller groups (approximately 8 persons) in order to facilitate interaction. Time was set aside to provide the students with opportunities to get to know each other and to discuss principles for how to maintain contact via computer conferencing.

FirstClass (course 1) and WebBoard (course 2) were used for the dialogue among the participants. Although both support synchronous and asynchronous text based communication, only asynchronous communication was prescribed for these courses. Forums for social as well as task related (cognitive) interaction were created and the students could take part in all contributions to the conference. At the first meeting, the learners were introduced to use of the technical communication tools, and additional technical support was obtainable from the University.

Table 1: Description of the student groups

\begin{tabular}{|l|l|l|}
\hline & \multicolumn{1}{|c|}{$\begin{array}{c}\text { Course } 1 \\
\text { (undergraduate) }\end{array}$} & \multicolumn{1}{c|}{$\begin{array}{c}\text { Course 2 } \\
\text { (Masters) }\end{array}$} \\
\hline Number, gender & 33 (8 men, 25 women) & 29 (29 women) \\
\hline Average age & $36(24-48)$ & 47 (25-53) \\
\hline Computer experience & $91 \%$ (30 students) & $93 \%$ (27 students) \\
\hline Communication tool & FirstClass & WebBoard \\
\hline Experience with the communication tool & $6 \%$ (2 students) & $100 \%$ \\
\hline Previous university studies & $20 \%$ (7 students) & $100 \%$ \\
\hline Previous distance studies & $15 \%$ (5 students) & $100 \%$ \\
\hline Engaged in professional work & $67 \%$ (22 students, 6 FT) & $97 \%$ (28 students, 17 FT) \\
\hline
\end{tabular}

A majority of the students were women (Table 1). Most of the students were experienced with word processing and using email. A majority of the students combined trade work with studies. In course 2 the students worked within the same area as the course content was based on, while the students in course 1 had widely varying professional backgrounds. Most of the students in course 1 had no previous experience with university studies, distance studies or the computer conference system. In course 2, on the other hand, all students had experience of university studies (at least 180 credit points). All were experienced in using the communication tool and had engaged in distance studies earlier (between 10 and 70 credit points).

\section{Method}

Data about the students and the courses were collected from questionnaires (Q1) at the beginning of the courses, study guides, and course information material (Table 2). 
Table 2: Methods for collecting data

\begin{tabular}{|l|l|}
\hline \multicolumn{1}{|c|}{ Course 1 (N=33 students) } & \multicolumn{1}{c|}{ Course 2 (N=29 students) } \\
\hline Study guide and course information material & Study guide and course information material \\
\hline Questionnaire at course start (Q1) & Questionnaire at course start (Q1) \\
\hline Study diary (SD) & Questionnaire at course end (Q2) (22 students) \\
\hline Analysis of contributions in FirstClass & Analysis of contributions in WebBoard \\
\hline Interview (I) 10 students & Interview (I) 6 students \\
\hline
\end{tabular}

The students in both distance courses were asked to keep a diary (SD) once a week. A paper version of the diary was distributed at a campus meeting. The students could write freely but were encouraged to describe family, work and leisure in relation to their studies, the course and the significance of the study group. Moreover, the diary contained a structured part with questions on students' perceptions of how peer learners' contributions had facilitated their studies and learning. The diaries were collected at the end of the course. However, the diaries from course 2 were too fragmentary and could not be used. Instead a questionnaire (Q2) was distributed. It contained questions (mostly open ended) about their experiences of hindrances and possibilities in distance studies, the significance of computer conferencing, and interaction with peer learners.

Interviews (I), with open questions took place during the last meeting at the University. The subjects for the interviews were the students' opinions of the course organisation and structure in relation to their everyday life, skills needed to manage distance studies, and the significance of computer conferencing and interaction with peer learners. The students' contributions in FirstClass and WebBoard were counted and divided into two categories, obligatory (task related) and spontaneous.

\section{Results and analysis}

Findings are presented in three sections: "Students' attitude to structure, dialogue and autonomy," "Students' expressions of social presence" and "Students' opinion of the interactions' significance for learning."

Quotations illustrate the learners' expressions. As the courses and investigations were conducted in the Swedish language the quotations were translated to English by the author. The quotations end with the informants' code, numbered from 1 to 33 (course 1 ) and S1 to S22 (course 2). In both cases, the informant's code is followed by information about from where the statement was retrieved.

\section{Students' attitudes to structure, dialogue and autonomy}

One important responsibility for teachers is to facilitate studies and learning. According to Moore (1997), distance teachers have to decrease TD by finding an appropriate balance between structure, dialogue and autonomy. He stated that TD decreases when the dialogue is high and structure is low. In this manner, courses can better be adapted to students' individual needs. Courses with a low degree of TD also lower the demands on the student to exercise autonomy (Moore, 1997).

The students had, apart from the fact that the course content seemed interesting, applied for the course because it was given as a distance course. They were dependent upon adapting their study time around obligations in their working and family lives. However, half of the students (in each course) would have preferred regular campus 
education if they had had the possibility to attend. They said that they missed collaboration and social activities with others in distance education settings. All students considered that distance studies require self discipline, organisational ability and autonomous capacity. Nobody emphasised the importance of having good communication or cooperation skills, which are essential proficiencies in order to interact with others. Thus, the students regarded distance education as a form of education that enables flexibility in time and individual learning. Their statements also indicated that flexibility is an important factor in carrying out their studies. The result, in that respect, does not differ from earlier studies (Moore 1997; Peters 2003; Holmberg 2003). A course design with a low degree of structure would therefore, according to Moore (1997), suit them. However, a majority of the students appreciated the courses' high degree of structure, as regards meetings at campus with contents planned beforehand and a study guide with strict instructions and timetables.

The students tended to regard lectures and on campus meetings as important for their distance studies. For example, "...excellent to be introduced to the subject field ... more frequent meetings would facilitate the studies..." (I, 29). A majority of the students considered that face to face meetings facilitated the dialogue, for example "...more frequent meetings to facilitate discussions ..." (I, S22). Some students stated that the meetings also helped elucidate and bring order to misunderstandings that may have occurred in the text based computer environment. Many students, especially in course 1, also considered that the meetings served an important social function and a possibility to build motivation to carry out the studies. For eample, one student wrote in his diary: “... It becomes lonely sometimes... I am overloaded ... need to be inspired ..." (SD, 16). The students also felt that face to face meetings had a positive influence on the computer mediated dialogue. One student said "... It feels more comfortable to contribute to the conference if one has met the others beforehand..." (I, $1)$.

Nearly everyone enjoyed the study guide's high degree of structure. Clear instructions supported them in how to treat the course content. Timetables helped them to organise their studies and to maintain their self discipline. Some students said, for example, "... I believe that I would lose time if I didn't have the timetable... I must say that the structure in the study guide serves as a "stick" (promoter)..." (I, 13); “... the structure with timetables... was an important supporting factor..." (I, S21).

The students also considered the courses' high degree of structure as a disadvantage, especially the assignments with requirements for dialogue (interaction). Most of the students admitted that it was nice and worthwhile to receive feedback from peer learners, but having to comment upon contributions by others hampered them from allocating time more in accordance with their own needs. One students said, for example, "... It is inconvenient when one is obliged to interact - actually I cannot do so in my life... my way of organising and my study time do not fit with theirs..." (I, 14).

The analysis shows that students in both courses followed their instructions and interacted to the extent that was required, neither more nor less. They mostly summarised a peer learner's text and appended a positive and supporting statement (see also Östlund, 2005, 2007). Several students stated that the reason why there were no extended discussions was due to lack of time. For example, “... actually I work full time alongside my studies, therefore I have to observe some limitations... and read and write what I am obliged to, no more..." (I, S2); “... honestly, I commented upon 
other's texts if I had to..." (I, 10); “... I have a feeling that everyone did it (interacted) because it was obligatory to pass the course..." (I, S18). Several students also considered that "... the comments were mediocre..." (I, S21); “... the texts were mostly a repetition of the literature and the comments were mostly kind and smooth Excellently typed!!!" (I, 14). In this case it seems that the students were pragmatic in their studies with a short term, "just complete the course" idea placed before learning together with others, since collaborative learning is time consuming.

However, students appreciated the less structured dialogue and enjoyed the possibility to interact with peer learners if required and when they had the opportunity (33 students in course 1 and 20 students in course 2). The students also made many spontaneous contributions to FirstClass and WebBoard (see Table 3). They thought that computer conferencing was effective for short messaging, elucidating unclear points and communicating social items. For example. "...you send a mail and get nearly immediately answers. You don't have to waste time waiting..." (Q2, S24). A student in course 1 wrote that the peer learners had "...supported him to continue the course..." $(\mathrm{SD}, 25)$. Another student pointed out that the interaction had resulted in "...increased self confidence and self esteem when I understood that others, too, perceived the literature as difficult ..." (SD, 15). The students also enjoyed the asynchronous communication since they did not have to be online at the same time and because it gave them the possibility to "...print out documents and discussions and consider the content several times..." (Q2, S2)

The students in course 1 also interacted synchronously via a chat room. It was on their initiative and almost all of the students participated in and valued the synchronous communication. According to them the chat fulfilled an important social function. Several students also stressed the fact that it increased their study motivation "Every Thursday we meet at our chat room... and I believe that my motivation to study is greatest on Thursdays and Fridays after the chat..." (I, 3). Synchronous communication was also used to support each other to get a clear picture of how to understand assignments, for instance: "Do you understand what the teacher means...?" (I, 3). The students perceived, however, that it was difficult to initiate a discussion. A group of approximately eight persons was too big, according to the students, and several of them argued that it became difficult to follow discussion threads "...someone types a question and someone else replies to a previous question... it is not easy to synchronise the contributions in the discussion." (I, 4)

Conclusions that can be drawn from this study are that the students felt ambivalent towards structure, dialogue and autonomy and that the relations between the variables are not as obvious from the students' perspective as Moore (1997) found.

Both courses had a high degree of structure with respect to content, time and space. According to Moore (1997) the greater the structure is in a program, the less the autonomy the student has to exercise. The study shows however that the students valued the course's high degree of structure (regarding meetings and timetabled assignments), because they could hand over responsibility and control to the teacher, i.e. they did not have to exercise autonomy. This indicates that the students' perception of the relation between the variables structure and autonomy was the opposite of Moore's (1997) statement. The students' perceptions can be interpreted as, because of their life situation (with professional and family commitments), they did not want to use time on deciding what to learn of the course content, how and in 
which order they should do it. They "saved" time on renouncing autonomy. Another explanation for why the students appreciated a high degree of structure is that they did not have sufficient capacity for autonomous learning, as many distance students may belong to a generation whose schooling was characterised by teacher centred pedagogy and little scope for autonomy (Holmberg 2003). Therefore they probably felt more secure with a high degree of structure.

Students appreciated compulsory on campus meetings (high structure), despite reduced flexibility. Among other things, they felt that face to face meetings facilitated dialogue and decreased the scope for misunderstandings. Consequently, increased structure may sometimes increase dialogue, according to the students. On campus meetings also facilitated computer based interactions, as students became acquainted.

The teachers sought to promote better conditions for interactive learning by formulating assignments where dialogue was obligatory (high structure). An explanation for the students' adverse attitude to dialogue structured by the teacher is that it was time consuming and reduced the possibilities for combining studies with commitments in their everyday life. In this case the students wanted autonomy but the high degree of structure was perceived as a negative influence.

Nevertheless, the students emphasised the importance of having the opportunity to interact with peers. But their statements also point out that the dialogue must be based on the students' own needs and conditions. Spontaneous dialogue with peer learners gave support in times of need and did not restrict the students' everyday life.

\section{Students' perceptions of social presence}

The computer conferencing facilities in FirstClass and WebBoard were appreciated by the students. These facilities are used mainly for text based asynchronous communication, although they also provide for synchronous communication. As audio and video technology was not obtainable in the versions that were used, these tools had a low capacity to signal social presence (Short et al., 1976). Some students also considered that it required too many "key prints" in order to find new contributions. One student said, for example, that the discussion threads became so extended that "...nobody noticed my contribution. You had to reverse twice to find it. It felt like the contribution disappeared..." (I, S21). This could have had a negative influence on perceptions of social presence and interactions between students, because a contribution that nobody reads or replies to can give the feeling that a personal recipient does not exist "on other side the display" (Short et al., 1976).

Despite the deficiencies in the computer communication tools, the students' statements and actions in the conferences demonstrated that they experienced social presence and that they considered themselves as a group in more than an administrative sense. Some examples follow below from course 1 (corresponding contributions exist also in course 2).

Students made many spontaneous contributions (Table 3), took note of peer's problems, and used informal language: "We have winter in X-town. I agree with Karin's idea about taking a beer or two the next time we meet at the university." (16); "Ricky! Don't be depressed for the failed recording! I also had disturbances and poor sounds on my cassette tape. So you have company in your distress. Soon we meet at 
the university and then we can discuss the injustices we have been subjected to. If you just smile, you'll see the sun comes shining through for you (a lyric)..." (20)

Students noticed if others were not participating in a conference: "Hello! Got in touch with Marianne today. She has had problems with the computer and therefore she wasn't able to join the chat last Thursday. This week she'll try to participate." (23).

Most contributions contained a personal introduction and/or closure phrases: "Hello! Here, comes my little story. Have a real nice weekend!!!!!" (19); “Okay then, I wishes a very good night to all my tired and stressed classmates, good night!!" (15).

Students used various types of meta-linguistic cursors as acronyms and emoticons in order to express feelings and to compensate for the lack of nonverbal communication: "...after some considerations I have decided to give up "sobbing*..." (22); "The displays went black. After 3 minutes, the computers restarted and my first thought was, YES I have saved my text. Everybody was happy!!!!!!!!!!” (3); “ “...ask for your forgiveness for not having answered your mails and cries for help; -)..." (8); "...good evening!! (the time is 00:01... zzzZZ)..." (30).

Many students looked forward to meeting: "Long for the meeting at the university in about three weeks, it will become super to see you again. Have a good time until than. Take it easy and don't study to hard..." (8).

A conclusion that can be drawn from this study, in agreement with other studies (Gunawardena \& Zittle, 1997; Picciano, 2002; Walther 2002; Kreijns, Krischner, \& Jochems, 2004; Richardson \& Swan, 2003; Swan \& Shih, 2005) is that the medium's capacity to convey social cues is not the only factor influencing students' feeling of salience of interaction partners in a computer mediated environment. In this case, the students' social behaviours through asynchronous text based communication could be due in part to having met on campus before having to communicate via the computer. This probably influenced the students' level of confidence and solidarity and thereby their tendency to interact and look for support from each other. Another possibly influential factor is related to the number of individuals the students were expected to interact with. In both courses, the students were divided into smaller groups (approximately 8 persons). Each student's contributions became more visible and they thus became less anonymous. The students were also aware of the fact that they were to study together for an extended period of time, which may have motivated them to become more involved with peer learners and to give more of themselves (Walther, 2002).

\section{Students' opinion of the interactions' significance for learning}

The students made many contributions in FirstClass and WebBoard (Table 3). However, they also wrote to peer learners' private mailboxes, and in course 1 they communicated synchronously in a chat room. Moreover, several students spoke to each other via telephone and a few met in person at some occasions.

Almost everyone stated that the computer mediated communication had facilitated their studies. The average number of contributions that each student sent to FirstClass and WebBoard respectively was approximately the same. However, the proportion of spontaneous contributions was considerably higher in course 1 compared with course 2 (67\% and $43 \%$, respectively). 
Table 3: Extent and nature of the contributions

\begin{tabular}{|l|c|c|}
\hline & Course 1 $(\mathrm{N}=33)$ & Course 2 $(\mathrm{N}=29)$ \\
\hline Contributions & 944 & 816 \\
\hline $\begin{array}{l}\text { Average number of contributions each } \\
\text { student sent in the entire course }\end{array}$ & 28.6 & 28.1 \\
\hline Obligatory contributions & $(2.2$ per credit point) & $(2.8$ per credit point $)$ \\
\hline Spontaneous contributions & $315(33 \%)$ & $469(57 \%)$ \\
\hline
\end{tabular}

The obligatory contributions had a task related (cognitive) content. As mentioned before, the students followed strictly the instructions as described in the study guide. If one comment on a peer learner's text was demanded, the students did so, neither more nor less. If the students were instructed to comment on every participant in the group, they did so. There were no extended discussions and the comments were mostly encouraging and in agreement with each other (see also Östlund, 2005, 2007).

The spontaneous contributions had cognitive, social or practical contents. Most often a contribution was followed by one and sometimes two replies from peers. The contributions attracting the most extended discussion threads had social or practical contents. In course 1 for example, a contribution about a car accident received 15 replies, a question about when to "chat" received 10 replies and a question about "whom to comment" had 8 replies. In course 2 a proposal to have dinner together received 23 replies. Other contributions that involved many students in course 2 where when a participant wrote that she had landed a new job (9 replies) and when a student showed pictures of her new baby ( 8 replies). This would indicate the contributions mostly served a social purpose in both courses. However, when comparing the two courses, the students' opinion of the significance of the interactions for the actual studies differed.

In course 1 the students emphasised the social and practical aspects of the interactions (35 statements, SD), for example: “...they have supported me and given me the energy to continue the studies ...made me understand that everyone has a life situation that contains both obstacles to, and possibilities for, studying." (SD, 25). The students also felt that interactions with peer learners were supportive when they had difficulties understanding how to interpret assignments and how to formulate their ideas in order to pass (27 statements, SD), for instance "... we discussed an assignment that everyone had interpreted differently..." (SD, 15). The interaction's significance for learning the subject matter was highlighted to a minor extent (19 statements)

The students in course 2 emphasised the interactions' cognitive purpose and content. Many students placed emphasis on the importance of reading peer learners' contributions, and being informed about their opinions and experiences related to the course subject (22 statements, Q2). One student stated that she had acquainted herself in an effective way "...with others ideas that promote my continuous development" (Q2, S14). Another suggested that she had acquired "...new methods of approaching the subject area..." (Q2, S15). Less frequently, students emphasised the social aspects of the interactions, or that they had supported each other in how assignments should be interpreted or formulated (7 and 8 statements, Q2).

Differences between the student groups' statements may be explained on the basis of their different amounts of experience with university studies, distance studies and the subject. 
A majority of the students in course 1 were not experienced with university or distance studies. It is possible that they felt insecure about what distance studies imply and the criteria for passing a course at a university level. Consequently they were to a greater extent in need of and motivated towards interaction with peer learners, for the purposes of receiving social and practical support. In other words they had a lower capacity for autonomous learning (Moore, 1997) than the experienced students in course 2. They had professional experiences from widely diverse areas and most of them were unfamiliar with the subject area of the course. Consequently, the students had difficulties in discussing the course content and in referring to each other's competences and experiences. This could be an explanation as to why the undergraduate students did not stress the cognitive aspects of interactions to the same extent.

By contrast, a majority of the students in course 2 were experienced with the university per se and distance studies. They probably felt comfortable in the study situation and therefore did not have the same need to discuss social and practical issues. Course 2 was also an advanced course within the same subject area as the students' professional work. Consequently, all of them had the same bases of knowledge, which probably influenced the fact that they underlined the cognitive aspect of the interactions. They benefited mutually from the experiences and knowledge that could be immediately useful in their professional life. One student said, for example: “...you learn how colleagues work and deal with different problems in their municipalities. It is of considerable value." (I, S21).

\section{Conclusion}

Social theories of learning have assumed a dominant position in learning research over the last two decades. According to these theories, interaction and dialogue are crucial for learning. However, some studies indicate that distance education students do not interact effectively in computer mediated settings even if the computer technology allows it. Research in this area has to a large extent been focused on how course design and technical communication tools influence the quantity and quality of interactions among students.

This investigation was based on a small number of students in two courses. Therefore it only gives an insight in these students' opinions. As a group, however, they do not differ substantially from the average distance student, and similar course designs are in common use (Högskoleverket, 2004). This can widen the relevance of the findings.

The findings indicate that the:

- students desired degree of structure, dialogue and autonomy seemed to alter depending on their perceptions of benefits in different situations

- relations between the variables are not as obvious from the students' perspective as Moore (1997) found, especially the relation between structure and autonomy

- students' statements, online behaviour and ways of expressing themselves in the computer conference indicates that they experienced social presence when using asynchronous text based communication

- students placed emphasis on the importance of having the opportunity to communicate with peer learners, when they had the time and need for it 
- students' previous experiences with the subject area of the course, and with university and distance studies have an influence on what they consider interlearner interaction signifies for studies and learning

What do these findings imply for teachers who wish to promote interactive learning in computer mediated distance education?

The findings suggest that there seems to be a gap between the teachers' commitment to social theories of learning and the students' concern to manage their time. In this study, teachers struggle to promote interactivity by task related arrangements, for example tighter structure and stronger enforcements. These arrangements seemed not be suitable for the students. The students' desired course design was influenced by their everyday life situation with professional and family commitments. They have to use their time effectively, fitting into their own schedules. Students stated that the collaborative learning activities were time consuming and that these activities reduced their ability to use their time at their own convenience. As a result they did not interact beyond requirements, and it is possible that the students' motivation to interact was determined by their desire to pass the course, not in order to get a deeper understanding by collaborating with others.

Consequently, to bring about dialogue and effective interactive learning, teachers have to take in account the students' needs. They have to arrange distance courses where students find that they gain more from active participation and interaction than they lose in flexibility. This is a challenge.

In this study, the students had started to know each other at a face to face meeting before using computer mediated communication, and according to the students this had facilitated their online communication. Students interacted spontaneously when they were looking for support in their studies or just wanted to socialise, especially in the introductory course with inexperienced students. These interactions were structured by the students themselves. They could participate when they had the time, need and mood, that is they could interact when they were motivated and the participation did not interfere with other commitments in their daily life.

The students' online behaviour and statements also indicates that they felt social presence and solidarity with other students in the course, despite using text based asynchronous computer mediated communication, a medium with low capacity to convey social cues. Communicators feel more engaged and involved in group processes when social presence is high, according to social presence theory (Short et al., 1976). However, this study indicates that the relationship could be the other way around, namely if communicators feel connected to a group, they become more engaged and more motivated to interact with each other, and increased interaction also increases feelings of social presence.

Consequently, activities aiming to support feelings of solidarity and engagement in a study group are as important as the choice of communication tool to promote dialogue and social presence in computer mediated distance education.

\section{Acknowledgement}

The study is a part of the project "Interactive learning in distance education" funded by the Swedish Research Council. 


\section{References}

Daft, R. \& Lengel, R. (1986). Organizational information requirements, media richness and structural design. Management Science, 32(5), 554-571).

Garrison, R. (2000). Theoretical challenges for distance education in the 21st century: A shift from structural to transactional issues. International Review of Research in Open and Distance Learning, 1(1). http: / / www.irrodl.org/index.php/irrodl/article/view/2/333

Gorsky, P. \& Caspi, A. (2005). A critical analysis of transactional distance theory. The Quarterly Review of Distance Education, 6(1), 1-11. http:/ / telem.openu.ac.il/hp_files/pdf/Gorsky.pdf

Gunawardena, C. N. \& Zittle, F. J. (1997). Social presence as a predictor of reported satisfaction within a computer mediated conferencing environment. American Journal of Distance Education, 11(3), 8-25.

Hara, H., Bonk, C. J. \& Angeli, C. (2000). Content analysis of online discussion in an applied educational psychology course. Instructional Science, 28(2), 115-152. [viewed Feb 2007, verified 24 Dec 2007] http: / / crlt.indiana.edu/publications/journals / techreport.pdf

Hammond, M. (2000). Communication within online forums: The opportunities, the constraints and the value of a communicative approach. Computers $\mathcal{E}$ Education, 35(4), 251-262.

Hammond, M. (2005). A review of recent papers on online discussion in teaching and learning in higher education. Journal of Asynchronous Learning Networks, 9(3). http:/ / www.sloan-c.org/ publications/jaln/v9n3/v9n3_hammond.asp

Haythornthwaite, C. (2002). Building social networks via computer networks: Creating and sustaining distributed learning communities. In K. A. Renninger \& W. Shumar (Eds.), Building virtual communities: Learning and change in cyberspace. Cambridge University Press.

Holmberg, B. (2003). Distance education in essence: An overview of theory and practice in the early twenty-first century. 2nd ed. Oldenburg: Bibliotheks- und Informationssystem der Carl von Ossietzky Universität Oldenburg (BIS)- Verlag.

Högskoleverket (National Agency for Higher Education) (2004). Uppföljning av Sveriges Nätuniversitet - Tillgänglighet, rekrytering och extra ersättning. Rapport 2005:49R.

Jung, I. (2001). Building a thoretical framework of web-based instruction in the context of distance education. British Journal of Educational Technology, 32(5), 525-534.

Kanuka, H., Collet, D. \& Caswell, C. (2002). University instructor perceptions of the use of asynchronous text-based discussion in distance courses. The American Journal of Distance Education, 16(3), 151-167.

Kear, K. (2001). Following the thread in computer conferences. Computers \& Education, 37(1), 81-99.

Kreijns, K., Krischner, P.A. \& Jochems. W. (2004). Identifying the pitfalls for social interaction in computer-supported collaborative learning environments: A review of the research. Computers in Human Behaviour, 19, 335-353.

Martindale, N. (2002). The cycle of oppression and distance education. Athabasca University.

Moore, M. G. \& Kearsley, G. (1996). Distance education: A systems view. Belmont, CA: Wadsworth.

Moore, M. G. (1997). Theory of transactional distance. In D. Keagan (Ed.), Theoretical principles of distance education. London: Routledge. pp 22-38.

Moore, M. G. (2007). Meeting the theorists in Europe. The American Journal of Distance Education, 21(2), 55-59.

Östlund, B. (2005). Stress, disruption and community - Adult learners' experiences of obstacles and opportunities in distance education. European Journal of Open, Distance and E-learning, 2005(I). http: / / www.eurodl.org/materials/ contrib / 2005/Ostlund.htm 
Östlund, B. (2007). Collaborative learning - If, Why and How? Unpublished.

Peters, O. (2003). Distance education in transition: New trends and challenges, 3rd edition. Bibliotheks- und Informationssystem der Carl von Ossietzky Universität Oldenburg (BIS) Verlag.

Picciano, A. G. (2002). Beyond students perceptions: Issues of interaction, presence and performance in an online course. Journal of Asynchronous Learning Networks, 6(1). http:/ / www.sloan-c.org/publications/jaln/v6n1/v6n1_picciano.asp

Richardson, J. C. \& Swan, K. (2003). Examining social presence in online courses in relation to students' perceived learning and satisfaction. Journal of Asynchronous Learning Networks, 7(1). http:/ / www.sloan-c.org/publications/jaln/v7n1/v7n1_richardson.asp

Rourke, L., Anderson, T., Garrison, D. R. \& Archer, W. (2001). Assessing social presence in asynchronous text-based computer conferencing. Journal of Distance Education, 14(1). [viewed Feb 2007, verified 24 Dec 2007] http: / / cade.icaap.org/vol14.2 / rourke_et_al.html

Rovai, A. P. (2001). Classroom community at a distance: A comparative analysis of two ALNbased university programs. The Internet and Higher Education, 4(2001), 105-118.

Short, J., Williams, E. \& Christie, B. (1976). The social psychology of telecommunications. London: Wiley \& Sons, Ltd.

Soller, A.L. (2001). Supporting social interaction in an intelligent collaborative learning system. International Journal of Artificial Intelligence in Education, 12(1), 40-62. [viewed Nov 2004, verified 24 Dec 2007] http:/ / aied.inf.ed.ac.uk/members01/archive/vol_12/soller/paper.pdf

Sproull, L. \& Keisler, S. (1986). Reducing social context cues: Electronic mail in organizational communication. Management Science, 32, 1492-1513.

Swan, K. (2003). Developing social presence in online discussions. In S. Naidu (Ed), Learning and teaching with technology: Principles and practices. London: Kogan.

Swan, K. \& Shih, L. F. (2005). On the nature and development of social presence in online course discussions. Journal of Asynchronous Learning Networks, 9(3). http: / / www.sloanc.org/publications/jaln/v9n3/v9n3_swan.asp

Säljö, R. (2000). Lärandet i praktiken i ett sociokulturellt perspektiv. Stockholm: Bokförlaget Prisma.

Wallace, R. M. (2003). Online learning in higher education: A review of research on interactions among teachers and student. Education, Communication $\mathcal{E}$ Information, 3(2), 241-280.

Walther, J. B., Boos, M. \& Jonas, K. (2002). Misattribution and attributional redirection in distributed virtual groups. Proceedings of the 35th Hawaii International Conference on System Sciences. [viewed April 2006, verified 24 Dec 2007] http:/ / www.hicss.hawaii.edu/HICSS_35/HICSSpapers/PDFdocuments/OSVWE02.pdf

Wheeler, S. (2005). Creating social presence in digital learning environments: A presence of mind. Featured Paper for the TAFE Conference, Queensland, Australia: 11 November 2005. [verified 24 Dec 2007] http: / / videolinq.tafe.net/learning2005/ papers/ wheeler.pdf

Wännman Toresson, G. (2002). Kvinnor skapar kunskap på nätet. Datorbaserad fortbildning för lärare. Akademiska avhandlingar vid Pedagogiska institutionen, Umeå Universitet Nr 62.

Berit Östlund, Master in science of psychology, Lecturer at the Department of Child and Youth Education, Special Education and Counselling, Umeå University SE-90187, Umeå, Sweden. Email: berit.ostlund@educ.umu.se 